\title{
Thinking on Linguistic Culturology in College Chinese Teaching
}

\author{
Yanju Jiang \\ Baoshan College of Traditional Chinese Medicine, Baoshan Yunnan, 678000, China
}

\begin{abstract}
Keywords: College Chinese, Classroom Teaching, Linguistic Culturology
\end{abstract}
\begin{abstract}
College Chinese teaching, integrating linguistic instrumentality, humanity, artistry, and aestheticism, is to conduct trait-oriented education on the premise of guaranteeing the Chinese education quality. Linguistic culture is an important part in college Chinese teaching, and is of great significance to improving the Chinese quality of students. Therefore, strengthening the research of linguistic culturology and permeating the idea of linguistic culturology into college Chinese teaching are of great practical significance. This article has made an analysis of the permeation of the idea of linguistic culturology into college Chinese teaching from the aspect of the connotation of linguistic culturology, with a hope to provide a proper support and reference for the carrying out of college Chinese teaching activities.
\end{abstract}

\section{Introduction}

As it is known, language and culture are closely associated with each other in Chinese teaching due to the subject character of Chinese, which is of great importance to promoting the education quality of Chinese. Therefore, in order to help students develop abilities of humanity and aesthetic judgment, it is necessary to properly permeate the thought of language and culture into the practice of college Chinese teaching, so that students can externalize the thoughts, feelings, and cultural accomplishment of their own via language expression and verbal expression to lay a foundation for cultivating students' intercultural communicative competence. Besides, language and culture are the basis for learning other subjects, play an important part in inheriting our country's traditional culture and promoting our national spirit. Thus, in respect of both the social function of linguistic culturology and the degree of the Chinese education circle' s emphasizing linguistic culturology teaching, the research and permeation of linguistic culturology into the practice of college Chinese teaching (which is the core curriculum of trait-oriented education) should be strengthened, and to promote students' language application ability and language communication ability should be taken as an important teaching goal, so as to properly guide the practice of college Chinese teaching.

\section{Linguistic Culturology}

In the early 1990s, the collapse of the Soviet Union had remarkably affected the society, politics and economy of Russia, and people's production and living also had greatly changed. Faced with culture conflicts, people had to re-assess and re-evaluate the numerous cultural concepts at that time, and adjust their views of life and values, so as to adapt their spirits and conceptions to the mainstream social thoughts to get a better development. Under such a social context, related Russian linguistic researchers became not satisfied with the analysis of language vocabularies in language culture in traditional meaning and the exploration of the cultural meaning of national languages any more, and started deep exploration of language and culture from the aspect of the interaction effect of language and culture on each other as a whole in the late 1990s. The linguistics culturology emerged [1] . Generally, the objects of study of linguistics culturology cover 8 aspects: anthropocentrism at the level of culture, language in the meaning of culture value embodiment system, interaction and correlation between language and culture, individual with linguistic personality and characteristics, language and culture at the highest level, ethnic characteristics reflected by national language, interpretation of text via language culture and applied language in text intervention, and emergence and acceptance of language culture. 
In terms of subject nature, the linguistics culturology is a new subject formed based on the cross interaction between the linguistics and the culturology, in which, with culture as an important theoretical basis, the forms, structures and functions of culture are analyzed, and comparison is made among different linguistic cultures, so to analyze the similarities and differences among different linguistic cultures and explore the development of linguistic culture. Permeating the linguistics culturology thought into current college Chinese teaching is to figure out the interaction and correlation between related languages and cultures contained in the teaching contents, and then provide a proper guidance to language teaching via culture analysis, so as to greatly improve the quality of college Chinese teaching, and help students obtain better development.

\section{Permeation of Linguistic Culturology Thought into College Chinese Teaching}

Since long ago, importance has been being attached to language teaching in college Chinese teaching, and even the explanation of linguistic language has been being focused on in teaching, both of which attract attentions of teachers and students. Actually, most college students have accepted Chinese teaching for a long time, and have a certain language foundation; while the teaching time designated to college Chinese (a community curriculum) is relatively less. Thus, focusing on language teaching is bound to exert adverse effect on the literariness of Chinese education, and limit the cultivation of students' humanistic quality. Therefore, the teachers in colleges and universities should properly permeate the thought of linguistic culturology education into Chinese teaching, and add aesthetic education and humanistic education while sticking to the instrumentality of Chinese subject, so as to make the cultivation of students' language competence, the enhancement of students' humanistic quality, and the improvement of students' aesthetic judgment accord with each other perfectly.

\section{Permeating the Linguistic Culturology Thought into the Process of Phonological Competence Cultivating}

In Chinese teaching in China, the cultivation of students' phonological competence mainly refers to helping students acquire the ability of communication and exchange with standard mandarin via teaching practice. To develop such an ability, not only teachers need to make basis analyses of polyphonic words and variant pronunciation, but students themselves also should have certain cultural accomplishment and attach importance to their reserve level. Only in this way, the students' phonological competence can be improved ${ }^{[2]}$. For example, during the explanation of the article titled by King Wuling of Zhao Shooting on Horse in Hu Dress ( “赵武灵王胡服骑射” ) most students will habitually mispronounce the character of “几” in the sentence of “则鄗几于不守也” into

“ jǐ ”. In such a case, the teacher should explain the different pronunciations of this character in different contexts in combination with its cultural background. Thus, the students can learn to select a proper pronunciation based on careful analysis, to enhance their phonological competence. Only the teacher properly permeates the thought of linguistic culturology into teaching, and combines pronunciation teaching with cultural analysis, can students be helped to have a better understanding of the correlation between characters and their pronunciations, and grasp the inherent meaning of characters, and can the effect of college Chinese teaching be improved.

\section{Permeating the Linguistic Culturology Thought into the Process of Cultivating Students' Word Understanding Ability}

Phonological competence is an important aspect in the cultivation of students' comprehensive quality in college Chinese teaching, and, relatively speaking, students' word understanding ability is more important, which will influence students' study of Chinese in future. Therefore, importance also should be attached to the teaching of word understanding, and the thought of linguistic culturology should be properly permeated into college Chinese teaching, so as to enhance the humanity of teaching, and raise the quality of teaching. 


\section{Different Meanings of Words in Ancient and Modern Times}

Affected by social environment and culture change in its development and evolution, the basic meaning of a word would certainly change, making it different in meaning in ancient and modern times. Specifically, a person who interprets a word occurring in writings in classical Chinese from its present meaning would certainly make a mistake. In view of this, Chinese teachers in colleges and universities also should properly permeate the thought of linguistics culturology, and let students make an analysis of word connotation in combination with the cultural backgrounds in ancient and modern times, so as to figure out the proper meaning of a word under different contexts. Based on language culture, students can understand the culture connotation of words better, and enhance their word understanding ability, to lay a foundation for future development ${ }^{[3]}$. Take the example of a sentence of “未尝不叹息痛恨于桓、灵也” (never be not grieved and regretted about the Emperor Huan and the Emperor Ling) from the Prior Memorial on Dispatching the Army ( “前出师 表” ). The word of “痛恨” should be noted. Teacher should explain the different meanings of this word in ancient and modern times, to guide students to properly understand this word. In this article, the word doesn't mean that Liu Bei hated the Han Emperor, but means that Liu Bei felt grieved and regretted about the passing away of the former emperor, and asked Liu Chan to develop his noble spiritual merits and behavioral habits, "associating with virtuous courtiers, and staying away from snobs” , to realize the goal of reviving the Han Regime. Introducing the thought of linguistic culturology into word understanding ability teaching can help students grasp the connotations of words, figure out the different meanings of words in ancient and modern times, and truly master the different meanings and different applications of words in ancient and modern times based on the analysis of words' development and evolution. In this way, the teaching effect can be improved.

Analysis of Nuance among the Synonyms

Rigorously, there is no absolute synonymy in the Chinese system. That's to say, no matter how close the meanings of two words are, there must be a nuance therebetween. If students cannot identify such nuance, they are liable to apply words improperly. Therefore, synonym discrimination should be focused on in college Chinese teaching. Given that that teachers simply explain the nuance between words obviously is insufficient to arouse the learning enthusiasm of students, and is not favorable to improving students' word understanding ability, it might be better for teachers to insert cultural analysis into language teaching, and let students understand the nuance among the synonyms and grasp the applications thereof in combination with the cultural backgrounds to improve their word application ability ${ }^{[4]}$. Take the example of the Marching in Wormwood ( “蒿里行” ). In the process of analyzing the personalities of Cao cao, teachers can list the comments on the personalities of Cao cao from the academic research circle: hero (英雄), ambitious person (香雄), unscrupulous careerist (奸雄) and conspirator (奸贼), and ask students to make their own comments on the personalities of Cao cao in combination with the background of Cao cao with reasons. Students should actively search and look up related information after class, and make research and discussions to develop their own opinions. Thus, students can figure out the nuance among the four words of hero (英雄), ambitious person (采雄), unscrupulous careerist (奸雄) and conspirator (奸贼) while understanding the personalities of Cao cao, and properly apply this method in future learning to obtain a good learning effect.

\section{Briquetting and Further Development of Idioms}

Idioms are an important element in the research of modern lexicology. Besides, idioms are closely related to culture. Most idioms were formed by briquetting some fables or historical events. Therefore, it is recommended to properly permeate the culture thought into idiom teaching, and analyze the formation of idioms based on the cultural background and the evolution in modern society, to let students understand the connotations of idioms better based on a knowledge of culture background of idioms, which is favorable to teaching. Take the example of the Death of Chonger, the Duke Wen of Jin. Before the lesson, teachers can ask students make proper preparations, such as figuring out which idioms were formed via briquetting in this article; or illustrate some idioms formed via briquetting 
other historical stories, and ask students to analyze the development and evolution of the meanings of these idioms throughout the long historical development. Through looking up materials, it is easy to find out that “approach death” ( “行将就木” ) and “retreat to avoid a conflict” ( “退避三舍” ) are idioms formed via briquetting in this article. In combination with the content of the article, it is easy to accurately understand the two idioms. In addition, students will find out several idioms derived from the Commentary of Zuo ( “左传”), such as “small tricks” ( “鸡鸣狗盗”), “distort the truth” ( “指鹿为马”), etc. This can facilitate students learning about historical cultures, improving their cultural awareness, knowing the formation of language and culture better, and becoming more conscious to Chinese learning, which is favorable to improving student's humanistic quality.

\section{Permeating the Linguistic Culturology Thought into the Process of Cultivating Students' Morphological Standardizing Ability}

As the society changes, both language and culture also constantly change, and such change does not just happen in pronunciation and word meaning, but also in morphology standardizing. Take Chinese characters as the example. A word has experienced various configurations throughout the historical changes. For respect to history, these different configurations are reserved in college Chinese, which is good for the development of Chinese traditional culture. Since that these configurations are different from the ones in standard use at present time, teachers must make particular analysis and explanation, so as to prevent students from misusing the configurations of words, and improve the quality of Chinese teaching. In the process of analysis and explanation, teachers are bound to integrate language and culture together to a certain extent. In reliance upon the thought of linguistic culturology, teachers can get better results of teaching ${ }^{[5]}$. Take the example of the Mourning the Passing ( “伤逝” ) written by Lu Xun. The “钞” (transcribe) from the expression of “钞些公文” (transcribe some official documents), and “胡” from the word of “模胡” (vague) are different from the current standard characters of the same meaning in configuration. For purpose of preventing students from forming a wrong writing habit due to the authority of Lu Xun's literary works, teachers should explain the emergence and development of interchangeable characters and variant characters with reasons, the ways of writing of some common characters in the past, and the proper matches of these characters under specific contexts. Notwithstanding, students should abide by the standard writing form for standardizing. Although such a simple explanation seems to have no influence, it can facilitate students paying more and more attention to morphology standardizing unconsciously, and gradually recognizing the evolution of words, to lay a foundation for further research in future for a better achievement.

\section{Conclusion}

In order to improve students' language communication ability and humanistic quality through college Chinese teaching, it is necessary to not only impart basic Chinese language knowledge to students, but also properly permeate the culture thought to help students understand language better via analysis of cultural background and improve the quality of teaching. That's to say, teachers should actively introduce the thought of linguistic culturology, and teach and guide students based on the linguistic culturology, to enhance the humanity of teaching, promote students' comprehensive quality, and help students' get better achievement.

\section{References}

[1] WANG Yangzheng. From Linguistic Ethnology to Linguistic Culturology. Journal of PLA University of Foreign Languages, 2011, 34(2): 27-31.

[2] ZHAO Aiguo. Philosophical Reflections on Basic Theories of Linguistic Culturology-On Academic Dividing Line between China and the West in Correlation between Language and Culture. Journal of PLA University of Foreign Languages, 2011, 34(1): 31-35. 
[3] KONG Weina. Cultivation of Intercultural Communication Competence under the Theoretical Framework of Linguistic Culturology. Heilongjiang University, 2014.

[4] WU Ya. Linguistic Culturology Analysis of Unit Connotation of Terminological Nomination of Russian and English Proverbs and Sayings. Journal of Inner Mongolia University (Philosophy and Social Science), 2012(4): 101-106.

[5] QU Yajing, ZHANG Yanan. Precedent Phenomenon of Ethnologic Culture in Linguistic Culturology. Journal of Changchun University of Technology (Social Science), 2013, 25(4): 132-135. 